\title{
Urban Parts Survey Methodology Based on Multi-level Positioning Grid of Spatial Information
}

\author{
HU Yin-cui, WANG Kun*, LIU Ming-yang, GU \\ Dong-li, XING Dan-lu, SONG Hai-li, SU Song, LIU \\ Yi-miao \\ College of Resources and Environment Science, \\ Hebei normal university \\ Hebei Key Laboratory of Environmental Change and \\ Ecological Construction \\ Hebei province, Shijiazhuang, P.R.China, 050024.
}

\author{
ZHANG Zhi-gang \\ Provincial Geomatics center of Hebei province, \\ Shijiazhuang, P.R.China, 050031.
}

\begin{abstract}
Urban parts database is infrastructure of digital urban management. To build urban parts database, investigation of urban management parts is nevertheless inevitable. The normal methods of survey include EDM (Electronic Distance Measuring Device) measurements, RTK and the CORS system measurement method. The location information of urban parts is obtained by expensive precision measuring instruments. Usually, the investigators have professional experiences of surveying and mapping. Due to cost on precision measuring instruments and training expenses, the survey methods will spend a lot of manpower, material and financial resources. However, the city management staff, responsible for inspections of components and events, with complex background is lack of knowledge of professional surveying and mapping. Thus, a simple, clear and accurate positioning method is needed which be able to comply with the basic requirements of the ordinary inspector. To meet the requirement, a new survey method is proposed in this paper. The method is based on the multi-level positioning grid of spatial information. The location information can be obtained quickly and accurately by integration of digital orthophoto map (DOM) and adaptive nine-tree multi-level spatial information grid. The integrated grid map can be displayed on the mini terminal, or be output to paper maps. The basic expression principles of map making are described. The accuracy of positioning is analyzed and the result is described. The practice shows that using this survey method could achieve the accuracy requirements of the urban parts management. The method is simple, easy to use and low operational costs.
\end{abstract}

Index Terms-Urban parts survey, Digital Orthophoto Map, Remote sensing image, Digital Line Graphic, nine-rectangle-grid.

\section{INTRODUCTION}

Urban parts database is the fundamental of digital urban management construction. To build the urban parts database needs to investigate the management parts of the city and update continuously, to check each management unit's location, ownership, responsible person, material, shape, code number and other basic information ${ }^{[1]}$. The positioning accuracy of urban component is divided into three categories. In the most accurate class A, the mean error is less than $0.5 \mathrm{~m}$ ${ }^{[2]}$. At present, The normal methods of survey include EDM (Electronic Distance Measuring Device) measurements, RTK

\footnotetext{
*WANG Kun: Corresponding author.

E-mail: wangkunzhuifeng@126.com tel:13831187631
}

and the CORS system measurement method ${ }^{[3]}$. The location information of urban parts is obtained by expensive precision measuring instruments. Usually, the investigators have professional experiences of surveying and mapping. Due to cost on precision measuring instruments and training expenses, the survey methods will spend a lot of manpower, material and financial resources. However, the city management staff, responsible for inspections of components and events, with complex background is lack of knowledge of professional surveying and mapping. Thus, a simple, clear and accurate positioning method is needed which be able to comply with the basic requirements of the ordinary inspector.

The update of the urban parts is frequently and the attributes of parts is complex. Digital City requires timing urban parts investigation. But, using EDM (Electronic Distance Measuring Device) measurements or RTK CORS system Measurements is difficult to guarantee real-time components updated. Even a period of update also requires a high cost. If city inspectors complete update work during their routine inspections process, it will save costs, increase efficiency and improve the urban parts content freshness.

The grid has become an important means in the digital city management. City Grid is the unit grid carrying responsibility, and the grid is irregular. Information investigator use City Grid to inspect area, and inspections are carried out daily on the area ${ }^{[4]}$. If this responsibility grid combines with positioning, the inspector will be able to do real-time updates of parts. Therefore, we can take advantage of this management characteristic and combine it with spatial location content, to real-time updates of parts maintenance. The difficulty of real-time update is the positioning of the parts. The inspector's professional background is complex. The inspector is different from the surveying and mapping professionals. Some of the city's inspector's education level is low, and some of the employments were laid-off workers. Thus, we need a simple, clear and accurate positioning method to comply with the basic requirements of the ordinary inspector.

Spatial Information Multi-grid can be used as a positioning reference of geographic features. The existing spatial information grid positioning uses quad-tree grid division positioning method which based on the ranks of coding ${ }^{[5]}$. In the practical application, the position encoder of this grid 
positioning method is complex, non-intuitive, and it does not meet people's discriminant orientation habits. In the regional area boundary or some special form area, this grid positioning method cannot be fast, accurate positioning. This causes difficulties for the determination of the spatial location, and easily leads to wrong judgment. Thus, it is necessary to extend the spatial information grid positioning method to make it more facilitate, fast and accurate in the positioning of the city parts or events.

This paper proposes a method to achieve quickly survey and locate of the urban parts, which is based on Spatial Information Multi-grid and superimposes the high-resolution remote sensing images of the management area, in order to save the cost, reduce technological dependence, improve the current trend of the urban parts content, and enhance the level of urban management.

\section{MULTI-LEVEL GRID OF SPATIAL INFORMATION}

\section{A. The concept of the multi-level grid of spatial information}

In remote sensing, remote sensing image is stored in the form of matrix; each matrix stores different gray value information which constitutes the whole image. Each matrix point is a grid.

Nowadays, the spatial information multi-level grid what we talk about is in accordance with different sizes of the grid to divide particular area (such as a binary tree, quad-tree and octree), at all levels grid in geographic scope have a relationship of the upper and lower covers. Each location of the grid is stored in the form of latitude and longitude coordinates in the center point of the grid, this center point is also recorded with a grid of closely related attribute data (e.g. latitude and longitude, geocentric coordinate, various projection parameters coordinates) ${ }^{[6]}$. The level of detail of the grid division is related of feature intensive within the region.

\section{B. The encoding and positioning method of the Multi-level grid of spatial information}

Adaptive nine-tree spatial information multi-level grid is to do basic grid division in the target area on the basis of target area of DOM or DLG, and determine the starting datum of the basic grid, then make the basic grid as the initial grid, on which the multistage nine-rectangle-grid network is divided. Multistage nine-rectangle-grid network is divided according to class-level as the first level, second one, and third one until the ninth level. Each level of nine-rectangle-grid network is divided into nine square grids with the same size, which are called Subdivision. The nine sub-grids are arranged into three rows and three columns. Each sub-grid implants nine-rectangle-grid network of the next level; every grid corresponds to the number from 1 to 9 respectively. The serial number of each grid in the whole grid system is arranged by a number of digital compositions, that is "the basic grid code + multi-level nine-rectangle-grid code". The code of the basic grid is marked according to the row-number; the code of the multistage nine-rectangle-grid sub-grid is expressed on the basis of level-number, the digits are determined according to the division level. Among them, higher-level numbers correspond to higher-level squared network coding, and vice versa. The geographic or the eventful spatial locations in the target area are determined in line with the grid encodings.

When dealing with the digital orthophoto map or the digital line graph, the multi-level grid positioning method mentioned above will only retain the outline of the geographic features.

The basic grid is marked by geographical coordinates or Cartesian coordinates. The geographical elements or events in squared net are classified according to their properties.

Geographic and eventful features in the target area need to do classification coding and positioning grid coding. Positioning coding will use multi-level nine-rectangle-grid network coding with spatial information; classification coding will adopt classification coding of geographic features from countries and professional sectors.

\section{Coordinate transformation}

Except positioning encoding, the information exchange will define the attribution and attribution codes. It also includes information storage, analysis and exchange, accurate real-time control, as well as the establishment of converted relationships for the multi-level nine-rectangle-grid network coding and spatial coordinates. These relationships include the Cartesian coordinates (X, Y) counting nine-rectangle-grid network coding, the squared network coding backcalculation Cartesian coordinates (X, Y), geographic coordinates (L, B) counting nine-rectangle-grid network coding, the squared Network coding backcalculation Geographical coordinates (L, B). Through the coordinate transformation, it will display in the master platform to achieve the accurate, real-time control for the geographic features and events in the space management.

\section{Accuracy}

Use this Spatial Information Multi-grid positioning technology to position city event or components. It won't be interference by feature environmental signals. Its accuracy can mainly be affected by the constraints of the ground resolution image maps, but its positioning data has high reliability. The positioning accuracy of instance experiment can reach $0.2-0.4 \mathrm{~m}$, achieving the accuracy requirements of large-scale topographic mapping.

Using adaptive nine-tree spatial information multi-level grid positioning method to make the geographic feature or event positioned in the target area. It can not only make position for locations without boundaries or with special features, but also form the multi-level grids in the determined region. It can determine the spatial position of the targets accurately and easily, and achieve real-time mapping. This method, used to represent geographic feature or eventlocation coding, is simple and fits people's habits of orientation discrimination. It makes the information collection faster and more convenient, which is efficient and cost savings. It is especially suitable for address coding census update, the urban-rural integration management, natural disaster relief, public emergencies, the comprehensive management of social 
order, public safety, materials management, community health, traffic navigation, fire and other industries.

\section{URBAN PARTS SURVEY METHODOLOGY}

According to the Spatial Information Multi-level grid positioning encoding method, to use digital orthophoto imagery or digital line graph, can assist people to investigate components and events in the jurisdiction. Investigative steps are as follows:

- In accordance with the accuracy by the survey request, creating grid map used in outside acquisition. After superposition with the encoding map of regional spatial information multi-level positioning grid, Digital orthophoto map or DLG became the base map for survey. The grid is divided according to the National Geographic grid ${ }^{[7]}$ standard.

- Print positioning grid coding imagery

- The investigators using the positioning grid encoding investigation base map on-site investigations. During on-site investigations, determines the position of the components in the investigation base map, to read the multi-level code of where the cell of the grid located. As shown in TABLE I, the unit grid where the basic grid position is the first 01 line 33; multi-level grid encoding 431, where the unit position encoder is 4(level 1), 3(level 2), 1(level 3), 0133,431 a space grid encoding, you can determine "without water" the spatial location of the incident, the events of the incident, strength and additional information in the information reported, can also be reported at the same time, as shown in TABLE I. In municipal management, municipal area demand for spatial information multi-level grid divided each grid segments encoding unit grid where the line number, column number, and a multi-level grid encoding uniquely determined.

- Through communication networks, put the survey data transmitted to the main control center.

- The main control center handling. System platform accept data or import storage media data, check the data, complete data storage and update. According to Spatial Information Multi-grid coding techniques to identify grid, through coordinate transformation to convert identify grid into geographic coordinates, unified storage location information and attribute information of this parts.

TABLE I. Multi-level spatial grid Location encoding

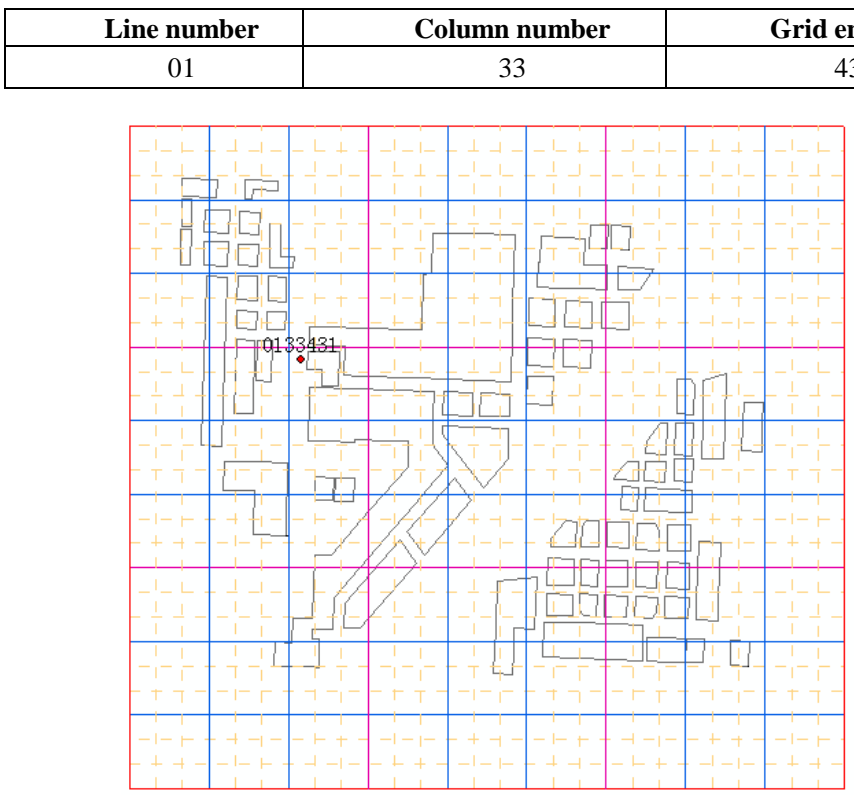

Fig.1. Object events in the map

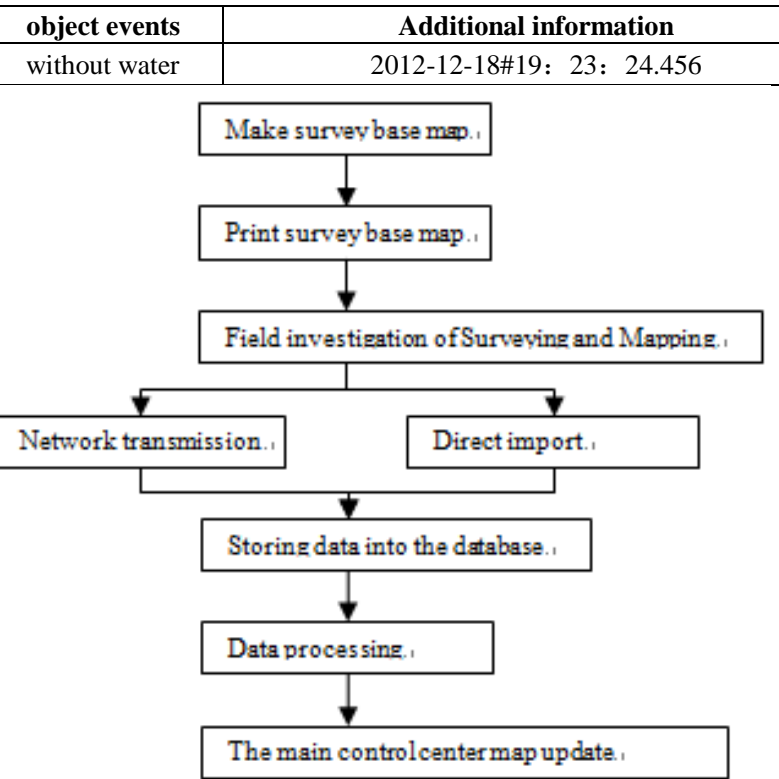

Fig.2. Survey flowchart based on multi-level spatial grid positioning

TABLE II. Analysis table of several ground resolution imageries

\begin{tabular}{|c|c|c|c|c|c|}
\hline $\begin{array}{c}\text { Image ground } \\
\text { resolution }(\mathbf{m})\end{array}$ & $\begin{array}{c}\text { mapping } \\
\text { scale }\end{array}$ & $\begin{array}{c}\text { grid } \\
\text { distance }(\mathbf{m m})\end{array}$ & $\begin{array}{c}\text { field grid } \\
\text { distance (m) }\end{array}$ & $\begin{array}{c}\text { Level-4 } \\
\text { Nine-rectangle-grid spacing (m) }\end{array}$ & $\begin{array}{c}\text { Level-5 Nine-rectangle-grid } \\
\text { spacing (m) }\end{array}$ \\
\hline 0.2 & $1: 500$ & 100 & 50 & 0.617 & 0.2 \\
\hline 0.4 & $1: 1000$ & 100 & 100 & 1.2 & 0.4 \\
\hline $\begin{array}{c}\text { Enlarge the print } \\
\text { image map s }\end{array}$ & $1: 10000$ & 100 & 1000 & 12.3 & 4.11 \\
\hline 5.0 & $1: 50000$ & 20 & 1000 & 12.3 & 4.11 \\
\hline
\end{tabular}

Multi-level grid of spatial information positioning sentenced painted method achieves real-time dynamic (synergistic) acquisition of geospatial information elements, ensuring that geospatial information will be renewed up to date, and saving expenditure. Mapping results fits the appropriate scale topographic mapping accuracy requirements. The smallest grid cells reach the level of the ground pixel resolution ratio. 
At the same time, using this multi-level positioning grid method of spatial information, true geodetic coordinates of the point values can be achieved spatial information confidential hide. Coordinate with the confidential requirements of the national spatial information.

\section{BASIC PRINCIPLES FOR LINE MAPS}

- Spatial Information Multi-grid grid lines designated color and digital line map (DLG) or digital image color coordinated, and highlights the program of grid lines.

- The Grid Line width should not be too large to minimize the background image of the gland.

- Grid lines the crossed type should not be complex, should adopt the single line.

- Basic grid coding annotation complements with map colors design.

TABLE III. Grid line drawing parameter table

\begin{tabular}{|c|c|c|c|c|c|}
\hline Line name & colors (Option 1) & transparency & color (Option 2) & line width $(\mathrm{mm})$ & Description \\
\hline The basic grid & Crimson & $100 \%$ & \multirow{3}{*}{$\begin{array}{c}\text { reference maps Framing } \\
\text { combined with Table }\end{array}$} & 0.3 & \multirow{2}{*}{$\begin{array}{l}\text { basic grid Note the } \\
\text { same color }\end{array}$} \\
\hline Two grid & Dark yellow & $50 \%$ & & 0.2 & \\
\hline Four grid & buff & & & 0.1 & Cross grid \\
\hline
\end{tabular}

\section{POSITIONING CODING ACCURACY ANALYSIS}

Take national basic scale mappable unit of 1:2 000 as an example, when the basic unit grid size is $200 \mathrm{~m} * 200 \mathrm{~m}$, adopting 3 nine-rectangle-grid subdivisions, and each subdivision mesh size is less than $7.5 \mathrm{~m} \times 7.5 \mathrm{~m}$; if adopting 4 nine-rectangle-grid subdivisions, each subdivision mesh size is less than $2.5 \mathrm{~m} * 2.5 \mathrm{~m}$.

Take national basic scale mappable unit of 1:10000 as an example, when the basic unit grid size is $1000 \mathrm{~m} * 1000 \mathrm{~m}$, adopting 3 nine-rectangle-grid subdivisions, and each subdivision mesh size is less than $37 \mathrm{~m} \times 37 \mathrm{~m}$; if adopting 4 squared subdivisions, each subdivision mesh size is less than $12.5 \mathrm{~m} * 12.5 \mathrm{~m}$.

TABLE IV. National basic scale maps 1:2 000, basic grid side length $=200 \mathrm{~m}$

\begin{tabular}{|c|c|c|c|c|}
\hline $\begin{array}{c}\text { Line } \\
\text { number }\end{array}$ & $\begin{array}{c}\text { Column } \\
\text { number }\end{array}$ & $\begin{array}{c}\text { Level } \\
\text { median }\end{array}$ & $\begin{array}{c}\text { digit of grid } \\
\text { coding }\end{array}$ & Unit grid (m) \\
\hline $2-3$ digit & $2-3$ digit & 3 digit & $3-4$ digit & $\begin{array}{c}i=3, j=7.5 \\
i=4, j=2.5\end{array}$ \\
\hline
\end{tabular}

TABLE V. National basic scale maps 1:10000, basic grid side length $=1000 \mathrm{~m}$

\begin{tabular}{|c|c|c|c|c|}
\hline $\begin{array}{c}\text { Line } \\
\text { number }\end{array}$ & $\begin{array}{c}\text { Column } \\
\text { number }\end{array}$ & $\begin{array}{c}\text { Level } \\
\text { median }\end{array}$ & $\begin{array}{c}\text { digit of grid } \\
\text { coding }\end{array}$ & Unit grid (m) \\
\hline $2-3$ digit & $2-3$ digit & 3 digit & $3-4$ digit & $\begin{array}{c}\mathrm{i}=3, \mathrm{j}=37 \\
\mathrm{i}=4, \mathrm{j}=12.5\end{array}$ \\
\hline
\end{tabular}

In this table, $\mathrm{i}$ is the breakdown of the series, $\mathrm{j}$ is the side length of the grid of the smallest unit.

\section{THE PROSPECT}

Urban parts investigation is a complex system engineering ${ }^{[8]}$. The survey method based on multi-level positioning grid of spatial information can reduce the difficulty of the job, and provide a new way of thinking for the construction of digital cities. The existing digital city construction is often to carpet survey to build a database of the city parts first, and then build a digital management platform, to achieve urban information management. The survey method which is based on space multi-level positioning grid need to build the digital management platform first, and then dynamic survey, build the database and update the urban parts at the same time, thereby reduce the initial investment of the digital cities construction and the cost of the database updating.

\section{ACKNOWLEDGMENT}

This paper is co-funded by Natural Science Foundation in Hebei Province (D2009000293), the Key Subject Construction Project of Hebei Province, Ph.D. Fund of Hebei Normal University (L2006B19).

\section{REFERENCES}

[1] LIU Jing. Components Acquisition on the Urban Grid Management [J]. Geomatics \& Spatial Information Technology, 2009, 32(1): $98-101$.

[2] TU Qiang, XU Wei. To Deal with the City Components Surveying Better is the Key Method of the Digital City Management [J]. Geomatics \& Spatial Information Technology, 2010, 33(3): 102-104.

[3] MA Shu-yong, WU Hui-huan, CHENG Peng-gen. The Application of CORS and Traditional Measurement in Urban Components Census Work [J]. Value Engineering, 2011, (10): 174-175.

[4] QIAN Ye-hong. Discussion on the Technology of Ten Thousand Meter Unit Grid Division [J]. Urban Geotechnical Investigation \& Surveying, 2009, (6): 29-30.

[5] LI De-ren, XIAO Zhi-feng, ZHU Xin-yan, GONG Jian -ya. Research on Grid Division and Encoding of Spatial Information Multi-Grids [J]. Acta Geodaetica et Cartographica Sinica, 2006, 35(1): 52-56.

[6] XIA Yu, ZHU Xinyan, LI Deren. Indexing Technology in Spatial Information Multi-Grid [J]. Geospatial Information, 2006, 4(6): 4-7.

[7] BAI Feng-wen, XU Hua-yan. The Applications of National Geographic Grid in Digital City Construction [J]. Bulletin of Surveying and Mapping, 2012, (4): 92-94.

[8] LIU Hong-jiang, CAO Yu-xiang, ZHANG Chang-rong, LIN Feng. Research and Realization on the Scheme of the City Component Data Collection of the Hangzhou Digital City Management $[\mathrm{J}]$. Urban Geotechnical Investigation \& Surveying, 2008, (2): 17-19. 